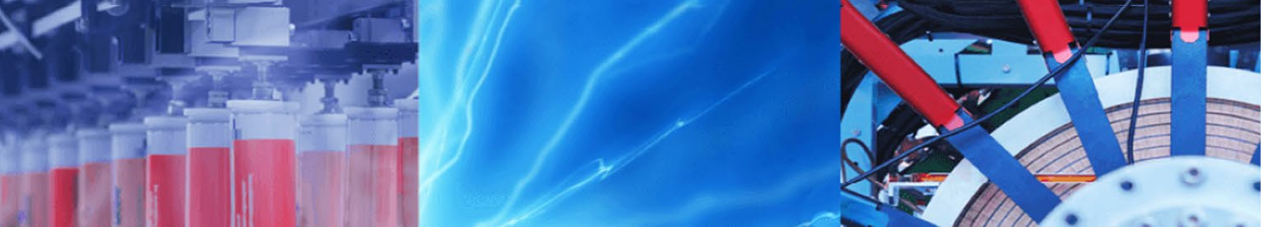

Research Article

\title{
Amorphous phase of volcanic ash and microstructure of cement product obtained from phosphoric acid activation
}

\author{
Benjamin Igor Djon Li Ndjock ${ }^{1}$ D $\cdot$ Jean Baenla ${ }^{2}$ Jean Baptiste Bike $\mathrm{Mbah}^{3} \cdot$ Antoine Elimbi $^{2} \cdot$ Martin Cyr $^{4}$
}

Received: 23 December 2019 / Accepted: 12 March 2020 / Published online: 20 March 2020

(c) Springer Nature Switzerland AG 2020

\begin{abstract}
Alkaline activation of volcanic ash using $\mathrm{Na}_{2} \mathrm{SiO}_{3}$ as activator showed its limits because of their low reactivity, nevertheless, phosphoric acid activation using $\mathrm{H}_{3} \mathrm{PO}_{4}$ as activator can offer a great possibility of utilization of the latter aluminosilicate. The present study aims to determine the chemical composition of amorphous phase of volcanic ash and examine through the microstructure of the obtained cement-based phosphoric acid activation the relation between silicon and phosphorus atoms. Chemical composition of amorphous phase was determined by dissolution with $\mathrm{NaOH}$ and $\mathrm{HCl}$. Cement fresh paste was subjected to isothermal calorimetry and temperature variation. Meanwhile, the hardened paste was characterized by X-ray diffraction, thermogravimetry analysis, scanning electron microscopy, energy dispersive spectrometry and Fourier transform infrared spectroscopy in order to study the microstructure. Also, the cement product was submitted to compressive strength test. The results obtained showed that, the amorphous phase of volcanic ash contain $\mathrm{SiO}_{2}, \mathrm{Al}_{2} \mathrm{O}_{3}, \mathrm{Fe}_{2} \mathrm{O}_{3}, \mathrm{MgO}$ and $\mathrm{CaO}$ oxides. This study allowed to understand the fact that phosphoric acid activation of volcanic ash at ambient temperature is an exothermic reaction and its described as a dissolution/precipitation process. Also, the obtained product was hydrated. Compressive strength of the cement product aged 1 and 28 days was respectively 20.6 and $30.5 \mathrm{MPa}$. Based on SEM/EDS analysis, silicon are partially replaced by phosphorus atoms and the product is made of -Si-O-Al-O-P-O-phospho-sialate network. Phosphoric acid activation is a promising route of valorisation of volcanic ash.
\end{abstract}

Keywords Volcanic ash $\cdot$ Amorphous phase $\cdot$ Partial replacement $\cdot$ Phosphoric acid activation $\cdot$ Cement $\cdot$ Exothermic

\section{Introduction}

Volcanic ash originates from volcanic eruption and depending on its chemical composition, it can be a potential natural raw aluminosilicate material for the synthesis of cements [1-6]. Its consists of very small particles composed of varying proportions of volcanic glass shards, minerals or crystals, and other rock fragment [7]. Ash is generated when solid rock shatters and magma separates into very small particles during explosive volcanic activity. It can be used for many applications such as in ceramics, as abrasive, in lightweight aggregates, cellular blocks, and concrete [5, 7]. Djon Li Ndjock et al. [8] studied the utilization of volcanic ash via alkaline activation and showed that it can be used either as a filler in cements or for cement synthesis depending on both the amount and molar ratio of $\mathrm{SiO}_{2} / \mathrm{Al}_{2} \mathrm{O}_{3}$ of its amorphous phase. Though it cannot substitute sand in civil engineering application, as a filler, but can allow an increase in the compressive strength of specimens. Moreover, at ambient temperature,

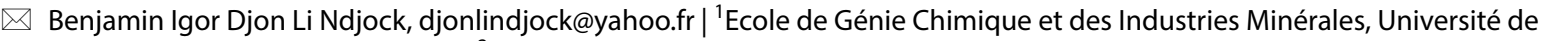
Ngaoundéré, Ngaoundéré, Cameroun. '2aboratoire de Chimie Inorganique Appliquée, Faculté des Sciences, Université de Yaoundé 1 , BP 812, Yaoundé, Cameroun. ${ }^{3}$ Laboratoire de Matériaux et de Chimie Inorganique Industrielle, ENSAI, Université de Ngaoundéré, BP 455, Ngaoundéré, Cameroun. ${ }^{4}$ Laboratoire Matériaux et Durabilité des Constructions, INSA/UPS Génie-Civil, Université de Toulouse, 31077 Toulouse Cedex 04, France.
} 
its utilization for geopolymer cements synthesis is limited as a result of low compressive strength [8-10]. This drawback may originate from its low content in reactive silica and alumina.

Acid activation is known to be used for the synthesis of magnesium phosphate cements [11-17]. Cements produced by this method can lead to compressive strengths of about $20 \mathrm{MPa}$ for specimens aged less than 7 days and $70 \mathrm{MPa}$ for specimens aged for 28 days [18-20]. These cements are also known as chemically bonded ceramic phosphates [13-15]. The high mechanical performance of the letter is due to the presence of crystalline product phases such as struvite $\left(\mathrm{MgNH}_{4} \mathrm{PO}_{4} \cdot 6 \mathrm{H}_{2} \mathrm{O}\right)[18,21,22]$ or $(\mathrm{K})$-struvite $\left(\mathrm{MgKPO}_{4} \cdot 6 \mathrm{H}_{2} \mathrm{O}\right)[11,23,24]$. Both the semicrystalline nature of magnesia and the exothermic reaction involved during its dissolution in phosphoric acid favour the formation of these phases $[13,15]$. The main drawback for the synthesis of magnesium phosphate cement is the high cost of magnesia. Acid activation is also used for the synthesis of phosphate based calcined clay cements [25-31]. In this case, maintaining the reactive medium at $60^{\circ} \mathrm{C}$ is generally helpful to get reliable cements [25-27, 29, 32-36]. The hardening of phosphate based geopolymers results in the formation of $-\mathrm{Si}-\mathrm{O}-\mathrm{P}-\mathrm{O}$, $\mathrm{Si}-\mathrm{O}$ and $-\mathrm{Al}-\mathrm{O}-\mathrm{P}-\mathrm{O}$ bonds by partial replacement of $\mathrm{SiO}_{4}$ tetrahedra by $\mathrm{PO}_{4}[33,37]$. This partial replacement have been observed firstly by Louati et al. [29, 34, 35] from FTIR in amorphous phase cement during the phosphoric acid activation of calcined clay. It will be interesting to verify by another analysis the partial replacement of silicon by phosphorus in the case of phosphoric acid activation of volcanic ash. Then, the aim of this work is to determine the chemical composition of amorphous phase of volcanic ash and the relationship between silicon and phosphorus atoms of cement product from SEM/EDS.

\section{Materials and methods}

\subsection{Materials}

The volcanic ash used in this study, denoted VA, originates from the volcanic deposit of Galim located $5^{\circ} 40^{\prime} 05^{\prime \prime}$ North latitude, $10^{\circ} 23^{\prime} 10^{\prime \prime}$ East longitude in the West Region of Cameroon. The collected samples were dried in an oven at $105^{\circ} \mathrm{C}$ (Heraeus oven, type VT $5042 \mathrm{EK}$ ) and ground using a planetary ball mill. The particles obtained were sieved through a $71 \mu$ m diameter sieve. Commercial phosphoric acid $\left(\mathrm{H}_{3} \mathrm{PO}_{4}, 85 \%\right.$ by mass) was used to prepare the activator by mixing acid and distilled water in order to get a solution of $10 \mathrm{M}$.

\subsection{Experimental methods}

The chemical composition of VA (Table 1) was determined by Inductively Coupled Plasma and Optical Emission Spectroscopy (ICP-OES) using a Perkin Elmer Spectrometer (Optima $^{\text {TM }} 7000$ DV ICP-OES) equipped with a CCD sensor. The amorphous phase content of volcanic ash was determined from its dissolution by phosphoric acid solution ( $3 \mathrm{M}$ ) with a liquid/solid mass ratio of 3.0 and mixing during one hour at room temperature. Nevertheless, due to the exothermic of the dissolution and the rapid precipitation of solid, in order to replace the latter approach, dissolution of volcanic ash in $\mathrm{NaOH}$ followed by $\mathrm{HCl}$ solution was used to determine the oxides contained in the amorphous phase according to standard ASTM C289 and French standard XP P18-594 [8, 38]. Also, $\mathrm{NaOH}$ solution was used to dissolve acid oxides of the amorphous phase whereas, $\mathrm{HCl}$ used to dissolve basic oxides and the precipitated acid oxides [38]. The obtained solution after dissolution in $\mathrm{NaOH}$ and $\mathrm{HCl}$ allowed to determine the amount of chemical elements such as $\mathrm{Si}, \mathrm{Al}, \mathrm{Fe}, \mathrm{Mg}$ and Ca by ICP-OES and the residue of VA after the dissolution was dried in an oven at $80^{\circ} \mathrm{C}$ for $24 \mathrm{~h}$. The XRD pattern of VA, residue of VA and cement powders were collected on a D8 Advance Bruker diffractometer, using copper radiation ( $\mathrm{Cu}, \mathrm{Ka}, \lambda=1.5406 \AA$ ). Pastes of cement (CEM) were obtained by mixing the activator solution with volcanic ash powder in a beaker (liquid/solid mass ratio of 0.47 ) for 2 min because of rapid hardening. The obtained cements pastes were cast in cylindrical moulds (diameter: $30 \mathrm{~mm}$; height: $60 \mathrm{~mm}$ ). Once moulded, the cylindrical samples were kept at room temperature $\left(27 \pm 3^{\circ} \mathrm{C}\right)$ and demoulded $24 \mathrm{~h}$ later for compressive strength measurement after 1 and 28 days according to EN 196-1 [39]. Compressive strength was determined using an electro-hydraulic press ( $M \& O$, type $1150, N^{\circ} 21$ ) at an average rate of $0.5 \mathrm{kN} / \mathrm{min}$. The results shown are averages of nine tested cylindrical shape specimens at each ageing day. A thermocouple (YC 747 UD service, Type K) was used to determine the variation of temperature during the hardening of paste. The thermocouple consisted of two wires of $\mathrm{Ni}-\mathrm{Cr}$ alloy, welded at one point. The junction of the two wires was inserted into the cement paste and then connected to a computer equipped with a Temps Monitor S32 software.
Table 1 Chemical composition of volcanic ash (VA)

\section{SN Applied Sciences

\begin{tabular}{lcccccccccccc}
\hline Oxides & $\mathrm{SiO}_{2}$ & $\mathrm{Al}_{2} \mathrm{O}_{3}$ & $\mathrm{CaO}$ & $\mathrm{Fe}_{2} \mathrm{O}_{3}$ & $\mathrm{~K}_{2} \mathrm{O}$ & $\mathrm{Na}_{2} \mathrm{O}$ & $\mathrm{MgO}$ & $\mathrm{MnO}_{2}$ & $\mathrm{TiO}_{2}$ & $\mathrm{P}_{2} \mathrm{O}_{5}$ & LOI & Total \\
\hline VA & 40.1 & 16.3 & 6.3 & 13.5 & 0.5 & 0.8 & 5.3 & 0.2 & 3.2 & 0.6 & 11.1 & 97.9 \\
\hline
\end{tabular}


The rate of heat released was monitored using an isothermal conduction calorimeter, TAM Air at $20^{\circ} \mathrm{C}$ for $48 \mathrm{~h}$. To this end, $5 \mathrm{~g}$ of paste and $3 \mathrm{~g}$ of water used as reference were respectively introduced in two different ampoules and loaded into the calorimeter. Thermogravimetry analysis on volcanic ash (VA) and cement (CEM) powders was carried out on a NETZSCH STA 449T by heating under argon from 50 to $1000^{\circ} \mathrm{C}$ at a rate of $10^{\circ} \mathrm{C} / \mathrm{min}$. In order to characterize the microstructure, prior to analyse, the sample was carbon coated by vaporization under vacuum for enhance electron conduction and placed inside the JEOL JSM-6380 instrument equipped with Energy Dispersion Spectroscopy (EDS) for chemical analysis, under accelerating voltage of $15 \mathrm{kV}$. The IR spectra absorption of volcanic ash and the obtained cement powders were measured on Bruker Alpha-p IR spectrophotometer in absorbance mode using the Attenuated Total Reflection (ATR) method. The IR spectra were recorded over a range of $4000-600 \mathrm{~cm}^{-1}$ at a resolution $1 \mathrm{~cm}^{-1}$ with 32 scans.

\section{Results and discussion}

\subsection{Mineralogical characterization of volcanic ash (VA)}

The XRD pattern of volcanic ash (VA) is given in Fig. 1. Analysis of the pattern revealed that $V A$ contains olivine forsterite $\left(\mathrm{Mg}_{1.42} \mathrm{Fe}_{0.58}\left(\mathrm{Si}_{0.99} \mathrm{Al}_{0.01}\right) \mathrm{O}_{4}\right.$ : PDF 87-10619), diopside
$\left(\mathrm{Ca}_{0.89} \mathrm{Mg}_{1.11} \mathrm{Si}_{2} \mathrm{O}_{6}\right)$ : PDF 87-0698), augite (Ca, Mg, Fe, Al)(Si, $\mathrm{Al}_{2} \mathrm{O}_{6}$ : PDF 70-3753), maghemite $\left(\gamma-\mathrm{Fe}_{2} \mathrm{O}_{3}\right.$ : PDF 89-5894), alkali feldspar $\left(\mathrm{Na}_{0.85} \mathrm{~K}_{0.15}\left(\mathrm{AlSi}_{3} \mathrm{O}_{8}:\right.\right.$ PDF 75-1635), feldspar plagioclase $\left(\mathrm{Ca}_{0.66} \mathrm{Na}_{0.34} \mathrm{Al}_{1.66} \mathrm{Si}_{2.34} \mathrm{O}_{8}\right.$ : PDF 12-0301), allophane $\left(\mathrm{SiO}_{2} \cdot \mathrm{Al}_{2} \mathrm{O}_{3} \cdot \mathrm{H}_{2} \mathrm{O}\right.$ : PDF 02-0039) and an amorphous phase. From TG of VA (Fig. 2), a mass loss around $410{ }^{\circ} \mathrm{C}$ is ascribed to allophane which is the only hydrated and semi-crystallized mineral observed in XRD of volcanic ash (Fig. 1). To get a better information about the chemical composition of the amorphous phase of volcanic ash, the amount of dissolved oxides contained in volcanic ash after selective dissolution in $\mathrm{NaOH}$ and $\mathrm{HCl}$ solutions were analysed. From the Table 2, amount of reactive $\mathrm{SiO}_{2}$ and $\mathrm{Al}_{2} \mathrm{O}_{3}$ in alkaline medium is greater than $\mathrm{Fe}_{2} \mathrm{O}_{3}, \mathrm{CaO}$ and $\mathrm{MgO}$. That is, $13.5 \%$ for $\mathrm{SiO}_{2}$ and $7.7 \%$ for $\mathrm{Al}_{2} \mathrm{O}_{3}$ against $0.2,0.1$ and $0 \%$ for $\mathrm{Fe}_{2} \mathrm{O}_{3}, \mathrm{CaO}$ and $\mathrm{MgO}$. In acid medium, the dissolution trend is different with $\mathrm{Fe}_{2} \mathrm{O}_{3}$ expressing the highest dissolution to about $6.8 \%$ followed by $\mathrm{SiO}_{2}, \mathrm{CaO}$, $\mathrm{Al}_{2} \mathrm{O}_{3}$ and $\mathrm{MgO}$ with $3.5 \%, 2.4 \%, 1.5 \%$ and $1 \%$ respectively. The trend observed must be due to the acidic and amphoteric characters of $\mathrm{SiO}_{2}$ and $\mathrm{Al}_{2} \mathrm{O}_{3}$ respectively compared to other oxides which are more basic. Also, the low dissolution of $\mathrm{Fe}_{2} \mathrm{O}_{3}$ in alkaline medium joins the observation done by Lemouga et al. [40], nevertheless, the present results reveal that the latter oxide is more soluble in acid medium. Moreover, Fig. 3 presents XRD pattern of volcanic ash after a dissolution by $\mathrm{NaOH} / \mathrm{HCl}$ solution. This pattern shows a considerable decrease of the amorphous phase, suggesting that reactive silica and alumina contained in
Fig. 1 XRD pattern of volcanic ash (VA)

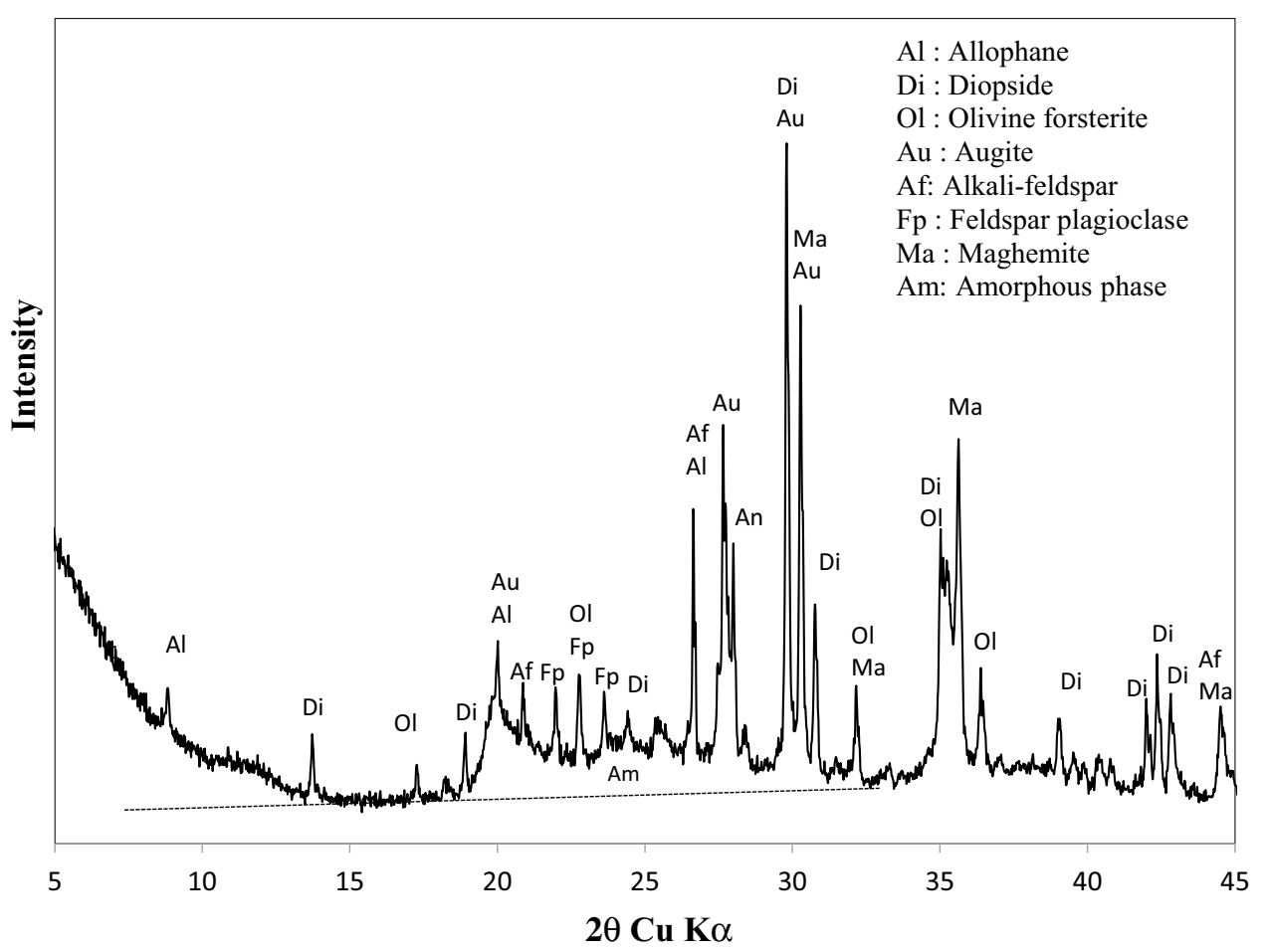

SN Applied Sciences 
Fig. 2 TG curve of volcanic ash (VA)

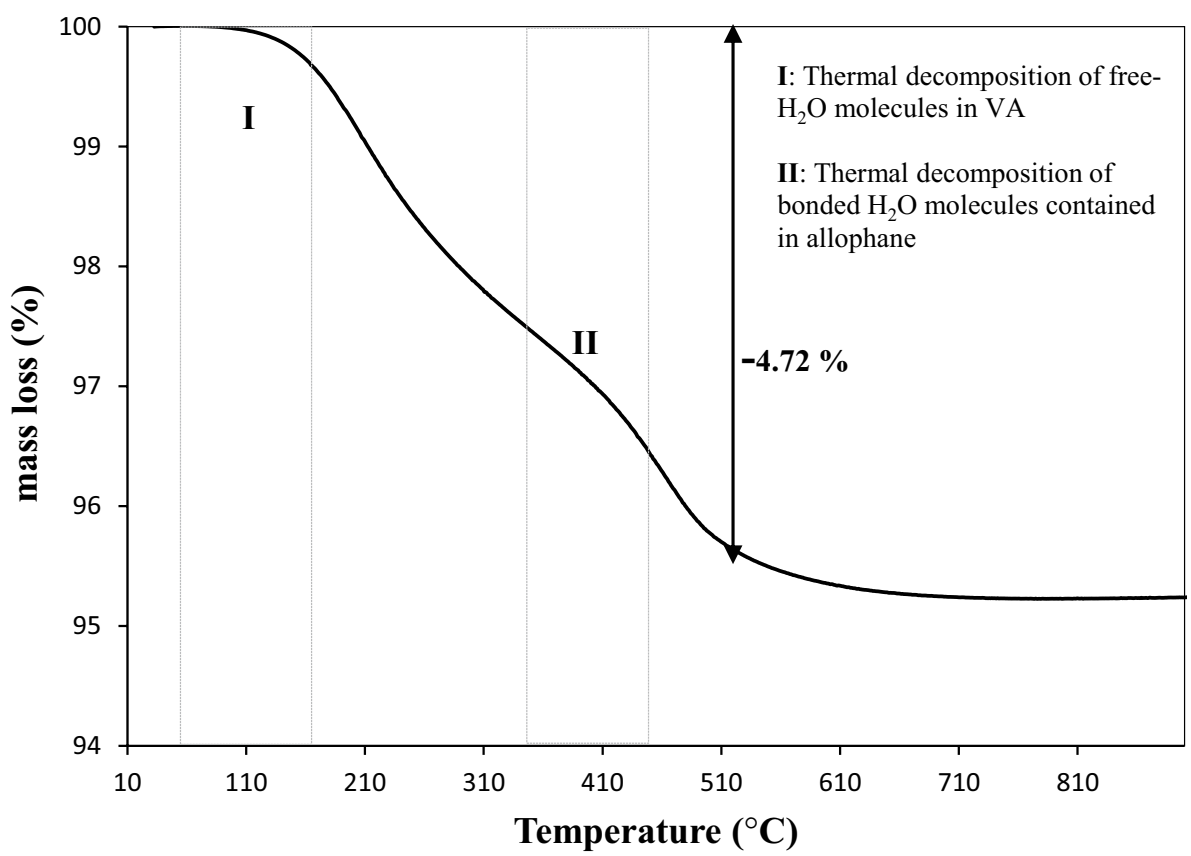

Table 2 Amount (\%wt) of reactive oxides released from volcanic ash (VA) in $\mathrm{NaOH}-$ $\mathrm{HCl}$ solution

\begin{tabular}{lll}
\hline Oxides & $\mathrm{NaOH}$ & $\mathrm{HCl}$ \\
\hline $\mathrm{SiO}_{2}$ & 13.5 & 3.5 \\
$\mathrm{Al}_{2} \mathrm{O}_{3}$ & 7.7 & 1.5 \\
$\mathrm{CaO}$ & 0.1 & 2.4 \\
$\mathrm{MgO}$ & - & 1.0 \\
$\mathrm{Fe}_{2} \mathrm{O}_{3}$ & 0.2 & 6.8 \\
\hline
\end{tabular}

volcanic ash may also originated from allophane. The shift in intensity of the hump before $\left(18\right.$ and $\left.45^{\circ}, 2 \theta\right)$ (Fig. 1) and after $\left(20\right.$ and $\left.38^{\circ}, 2 \theta\right)$ (Fig. 3 ) dissolution suggest that, the reactive phase of volcanic ash is silica-rich.

\subsection{Compressive strength and thermal evolution of the consolidation process}

Compressive strength of cement cured for 1 and 28 days at ambient temperature $\left(27 \pm 3^{\circ} \mathrm{C}\right)$ and aged for 1 and 28 days was respectively 20.6 and $30.5 \mathrm{MPa}$. Figure 4 shows the isotherm of heat flow during the first $48 \mathrm{~h}$ of phosphoric acid activation of volcanic ash. According to this Fig, a single exothermic peak is observed during the first three hours. This exothermic peak may correspond to the dissolution of oxides of volcanic ash by phosphoric acid. Also, its sharpness may reflect the precipitation of dissolved oxides. Figure 5 shows the cumulative heat released during phosphoric acid activation of volcanic ash. The obtained curve exhibits rapid increase of heat during the first eight hours. Heat released by this exothermic reaction increases over to $48 \mathrm{~h}$ period and corresponds to $49 \mathrm{~J} / \mathrm{g}$. Figure 6 shows the variation of temperature of phosphoric acid activated volcanic ash over time. During the first $200 \mathrm{~s}$ of activation, the temperature increases rapidly up to $58^{\circ} \mathrm{C}$. An increased in temperature of paste from ambient temperature to $63^{\circ} \mathrm{C}$ during the first $300 \mathrm{~s}$ is observed by Ai-juan et al. [41] during the synthesis of magnesium phosphate cements and they ascribed this increasing to chemical exothermic reaction. The latter observed also the fact that maximum temperature below $50^{\circ} \mathrm{C}$ reach the optimum compressive strength of $20 \mathrm{MPa}$ for $\mathrm{L} / \mathrm{S}$ ratio equal to 1.3 . The increase in temperature during phosphoric acid activation of volcanic ash confirms the observed exothermic reaction. Also, its might explain the compressive strength values of 20.6 and $30.5 \mathrm{MPa}$ respectively obtained after 1 and 28 days of ageing comparatively to alkali-activated volcanic ash at ambient temperature [8].

\subsection{X-ray diffraction and thermal analysis of cement (CEM)}

Figure 7 presents XRD pattern of cement (CEM) in which the broad hump are characteristic of the amorphous phase [42] ranging between 17 and $36^{\circ}$ (CEM). The area exhibited by the amorphous phase of CEM is larger than the one of VA (Fig. 1), and in spectrum there is no new crystalline phase. The amorphous phase of CEM originates from the reaction between phosphoric acid and crystalline and amorphous phases of volcanic ash. Figure 8 shows the TG/DTG curves of CEM. The TG/ DTG curves of CEM shows only one mass loss (14.98\%) at $105^{\circ} \mathrm{C}$ greater than mass loss (4.78\%) of volcanic ash 
Fig. 3 XRD pattern of volcanic ash after dissolution by $\mathrm{NaOH}-$ $\mathrm{HCl}$

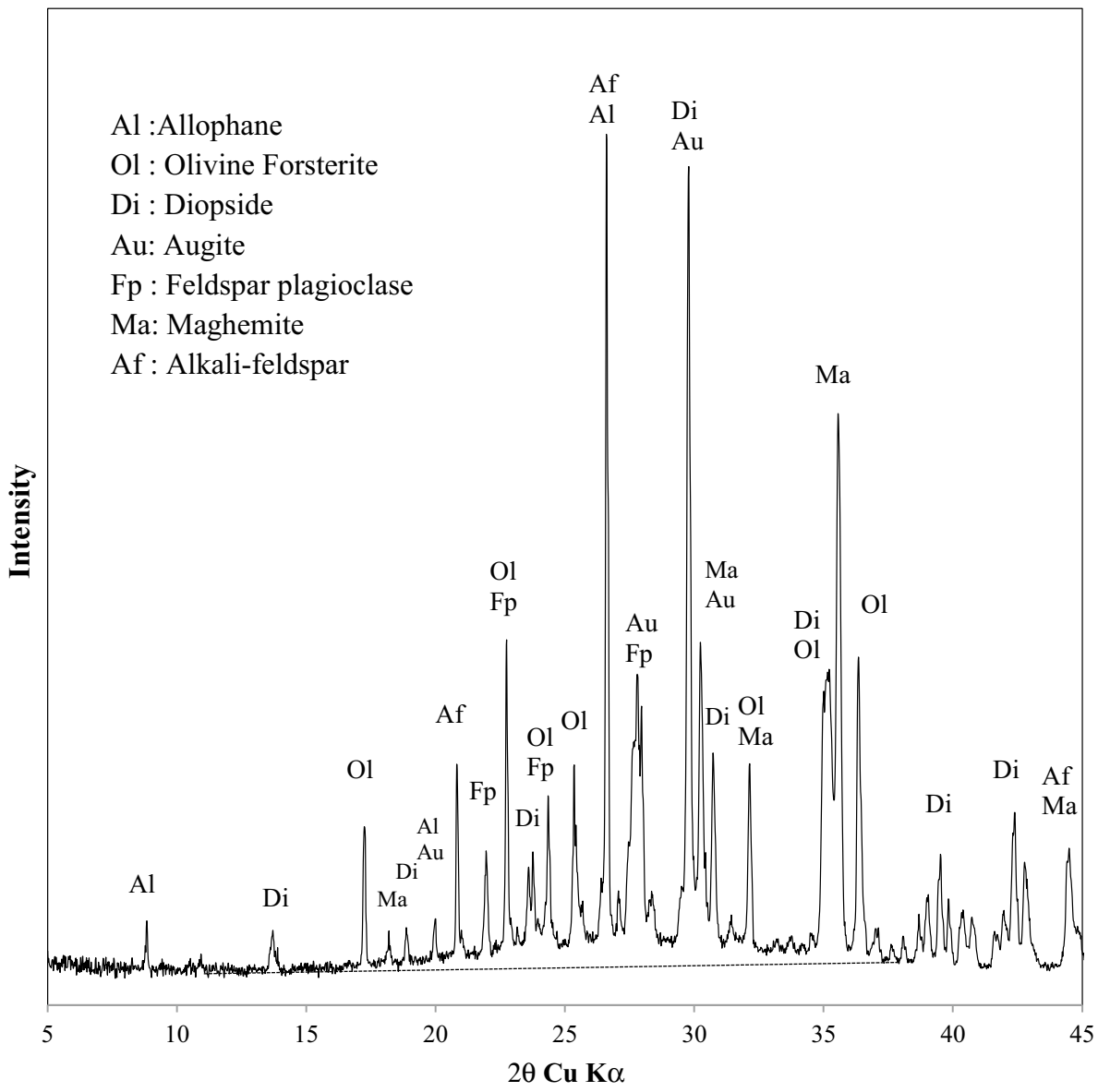

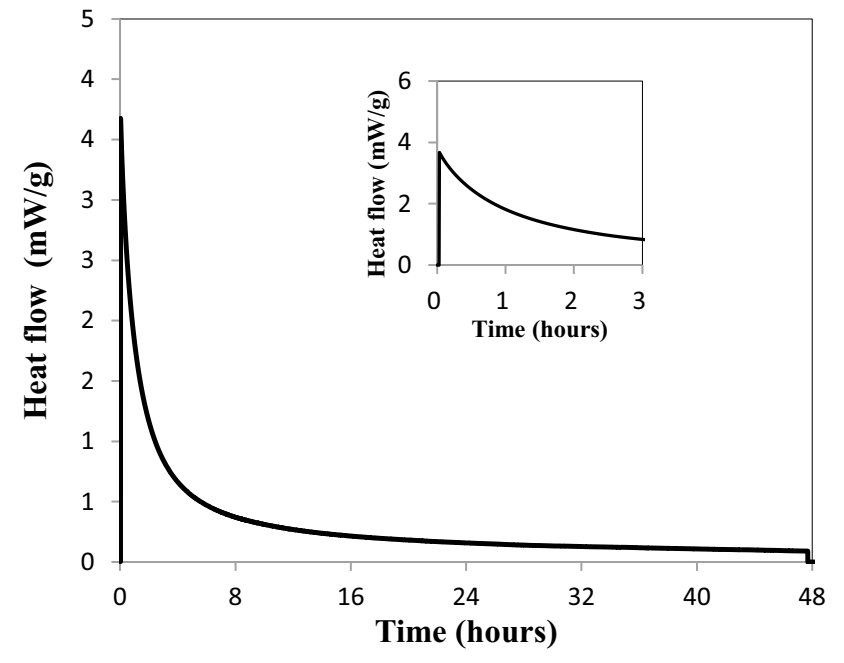

Fig. 4 Isotherm of heat flow during acid activation of volcanic ash (VA) at $20^{\circ} \mathrm{C}$

(Fig. 2). During phosphoric acid activation, the water that contain acid solution is absorbed and one part constitute the bonded water and another part constitute the

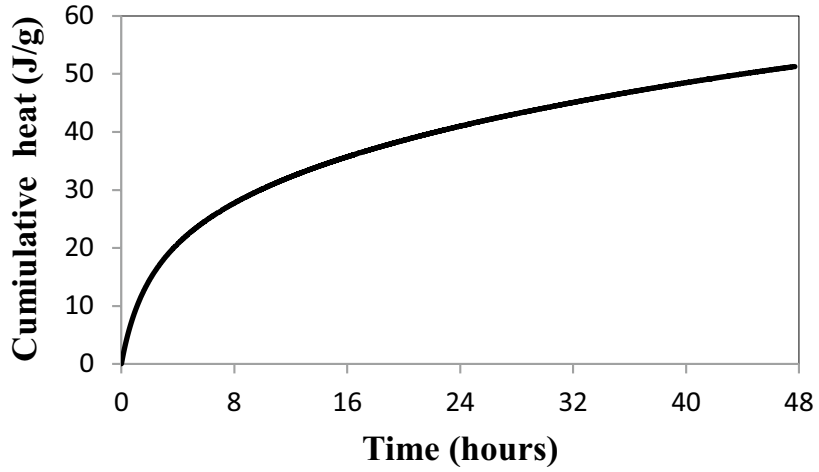

Fig. 5 Cumulative heat released during acid activation of volcanic ash (VA) at $20^{\circ} \mathrm{C}$

free water. Mohamed et al. [27] and Chengying et al. [30] observed the mass loss at $100-130{ }^{\circ} \mathrm{C}$ during thermal analysis of cement based phosphoric acid activation of metakaolin. They ascribed this mass loss to dehydration which indicate the loss of water from the phosphoric acid. Thereby, the mass loss observed of TG/DTG of CEM is ascribed to absorbed water during the activation. 


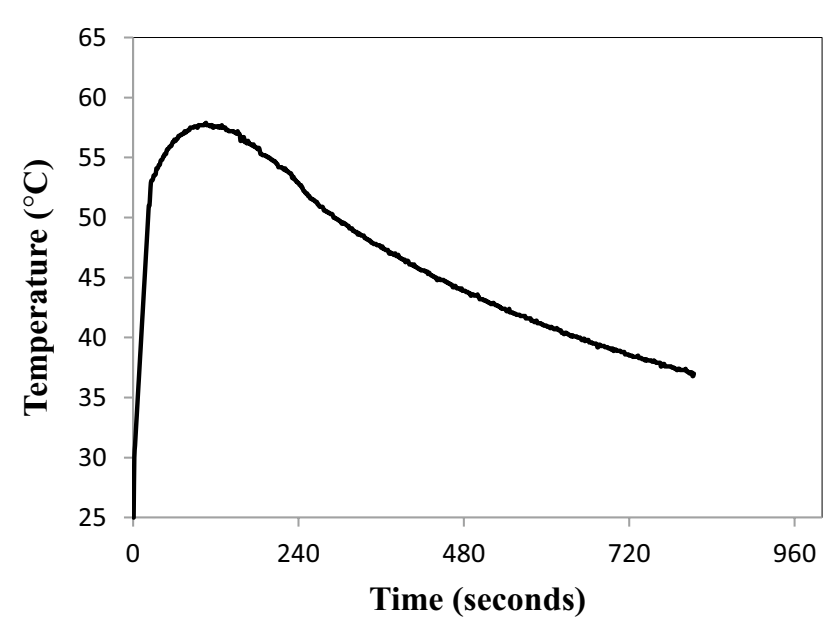

Fig. 6 Variation of temperature against time during acid activation of volcanic ash (VA)

\subsection{Microstructure of cement (CEM)}

SEM images of the CEM is given in Fig. 9. These images exhibits pores, cracks, unreacted particles along with compact domains. In order to determine the chemical composition of the compact domains observed in SEM (Fig. 7), EDS analysis was performed on fifty points of compact domains. In decreasing order, the compact domains are mainly composed of silicon, phosphorous, aluminum, calcium, and magnesium. The atomic distribution is plotted in various graphs (Figs. 10, 11 and 12). According to Fig. 10, the correlation between phosphorus and silicon atoms suggest the fact that, they are inversely concentrated in product such as when the amount of silicon increase, the amount of phosphorus decrease. The present observation in CEM may suggest the partial replacement of silicon by phosphorus in compact domain and in consistence with the works of Louati et al. [29, 34, 35], who observed the partial replacement of silicon atoms by phosphorus in phosphoric acid activated metakaolin by FTIR when molar ratio of Si/P decreased. Figures 11 and 12 presents the ternary diagrams between $\mathrm{P}$ and $\mathrm{Si}$ atoms with respect to calcium, magnesium, aluminium and iron. In the ternary diagrams, calcium and magnesium atoms are concentrated around $0.1 \mathrm{~mol}$ (Fig. 11a, b) whereas aluminium atoms are concentrated around $0.2 \mathrm{~mol}$ and iron atoms are concentrated around $0.3 \mathrm{~mol}$ (Fig. 12a, b). Also, the fact that the maximum amount of iron and aluminium are differents $(0.3 \mathrm{~mol}$ for $\mathrm{Fe}$ and $0.2 \mathrm{~mol}$ for Al) suggest their reaction with phosphorus atoms and their participation in the formation of product as observed by Bewa et al. [28] for laterite based geopolymer phosphate and Tckakouté et al. [26] for metakaolin based geopolymer phosphate. This participation of iron explain their great dissolution in acid medium (Table 2). In all ternary diagrams (Figs. 11 and 12), the maximum amount of silicon atoms is between 0.1 and $0.5 \mathrm{~mol}$ whereas for phosphorus atoms, the maximum

Fig. 7 XRD pattern of cement (CEM)

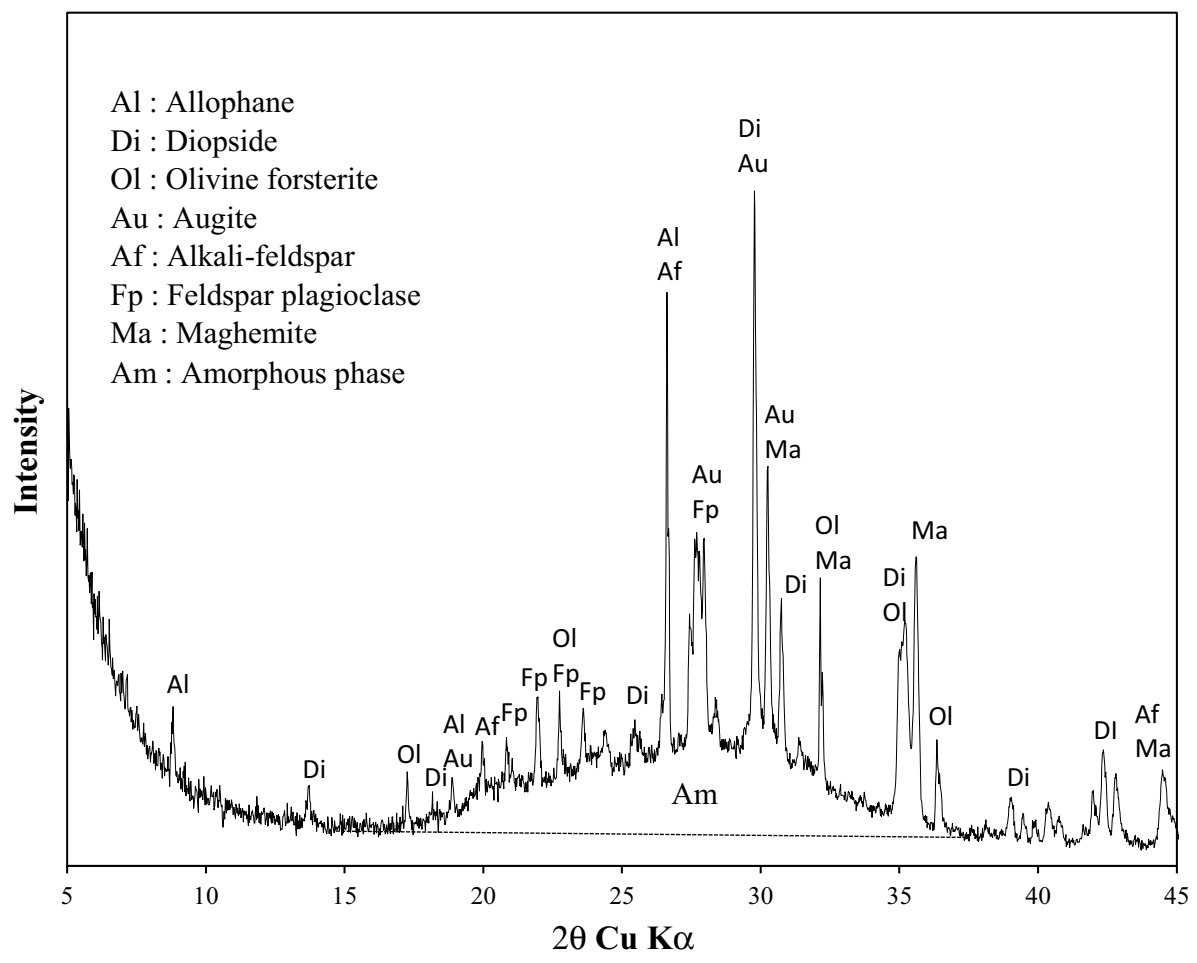




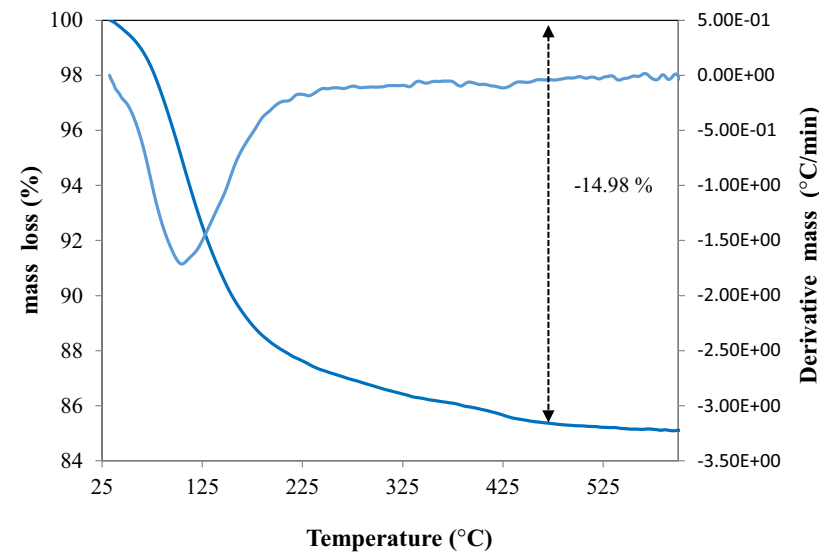

Fig. 8 TG/DTG curves of cement (CEM)

amount is between 0.5 and $0.9 \mathrm{~mol}$. This suggests that an important amount of silicon atoms was replaced by phosphorus during phosphoric acid activation. The FTIR spectra and the corresponding chemical groups of volcanic ash (VA) and cement (CEM) is given in Fig. 13. The bands at $3308 \mathrm{~cm}^{-1}$ and $1630 \mathrm{~cm}^{-1}$ are characteristic of the stretching and deformation vibration of $\mathrm{O}-\mathrm{H}$ and $\mathrm{H}-\mathrm{O}-\mathrm{H}$ groups in $\mathrm{CEM}$ indicate the presence of free and bonded water molecules [33, 35]. The broadness of these bands in CEM suggest the mass loss (14.98\%) observed in TG (Fig. 8). The bands at $1042 \mathrm{~cm}^{-1}$ and $955 \mathrm{~cm}^{-1}$ are a result of the linked bands between symmetrical stretching vibration of $\mathrm{Si}-\mathrm{O}, \mathrm{P}-\mathrm{O}$, and $\mathrm{Al}-\mathrm{O}[26,29,34$, 35]. The band at $955 \mathrm{~cm}^{-1}$ corresponds to $\mathrm{P}-\mathrm{O}$ vibration modes and induces the incorporation of $\mathrm{PO}_{4}$ units in the structure of cement $[26,29,34]$ and confirm the partial replacement of silicon by phosphorus atoms observed in Fig. 10. The appearance of two lower vibrational bands at $787 \mathrm{~cm}^{-1}$ and $729 \mathrm{~cm}^{-1}$ are ascribed respectively to $\mathrm{Si}-\mathrm{O}-\mathrm{P}$ and Al-O-P bond [26, 34]. Also, based on the vibrational bands of $\mathrm{Si}-\mathrm{O}-\mathrm{P}, \mathrm{Al}-\mathrm{O}-\mathrm{P}$ and $\mathrm{P}-\mathrm{O}$, and the fact that the local environment between aluminum and silicon and phosphorus atoms remained constant

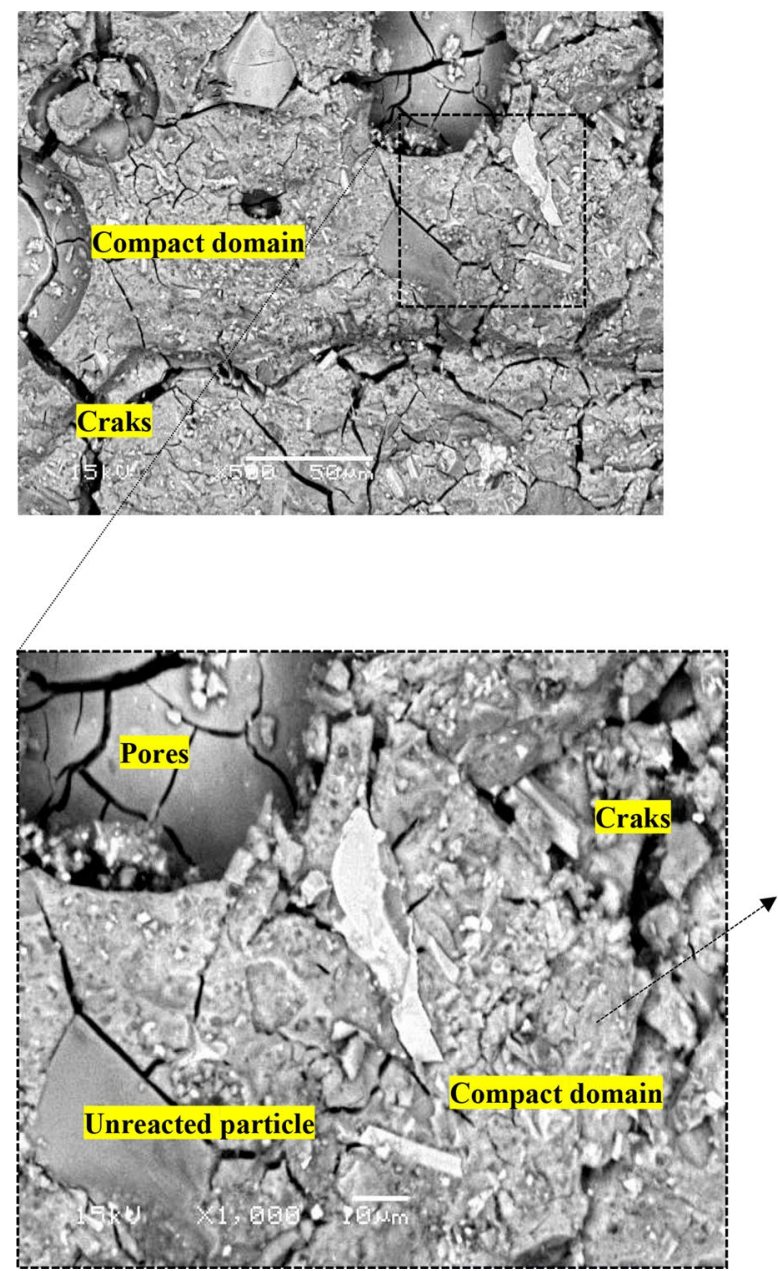

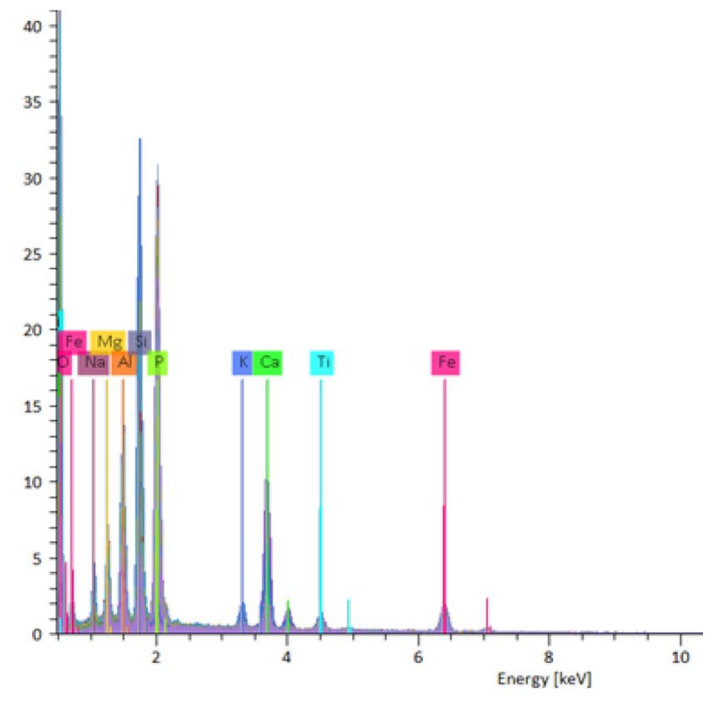

Fig. 9 SEM images and EDS spectrum of cement 


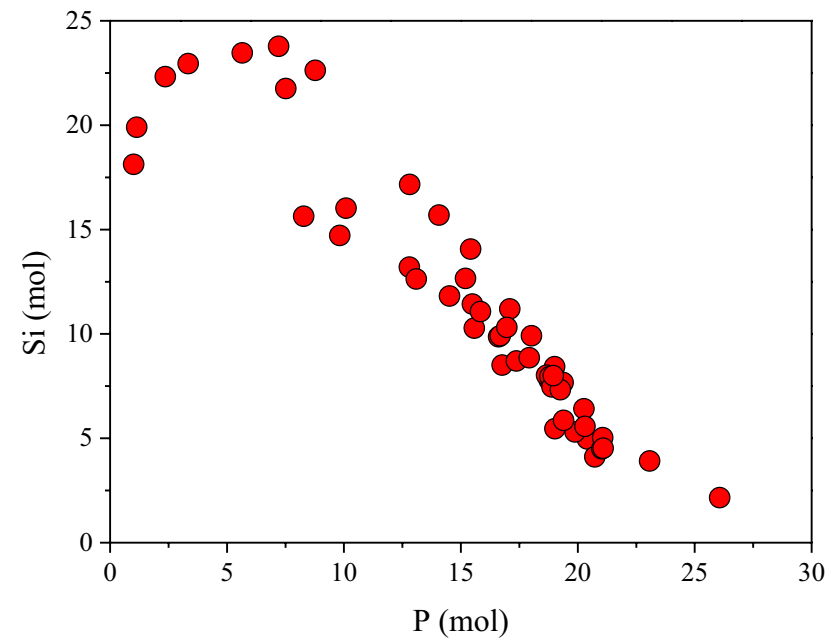

Fig. 10 Relation between Si and P atoms in cement

(Fig. 11C), then -Si-O-Al-O-P-O- phospho-sialate network is formed in the amorphous phase of the cement (CEM) [43]. Thereby, Figs. 10, 11, 12 and 13 respectively highlight firstly, the fact that iron and aluminum atoms have reacted with phosphorus atoms during the reaction and secondly, phosphorus atoms predominate over silicon in the amorphous phase of cement. Based on these observations, it can be concluded that, the cement product contain -Si-O-Al-O-P-O-phospho-sialate network in its structure.

\section{Conclusion}

This study focused on the determination of chemical composition of the amorphous phase of volcanic ash and examination of the microstructure of obtained cement by phosphoric acid activation at ambient temperature. From the results:

- The amorphous phase of volcanic ash contained $\mathrm{SiO}_{2}$, $\mathrm{Al}_{2} \mathrm{O}_{3}, \mathrm{MgO}, \mathrm{Fe}_{2} \mathrm{O}_{3}$ and $\mathrm{CaO}$ oxides.

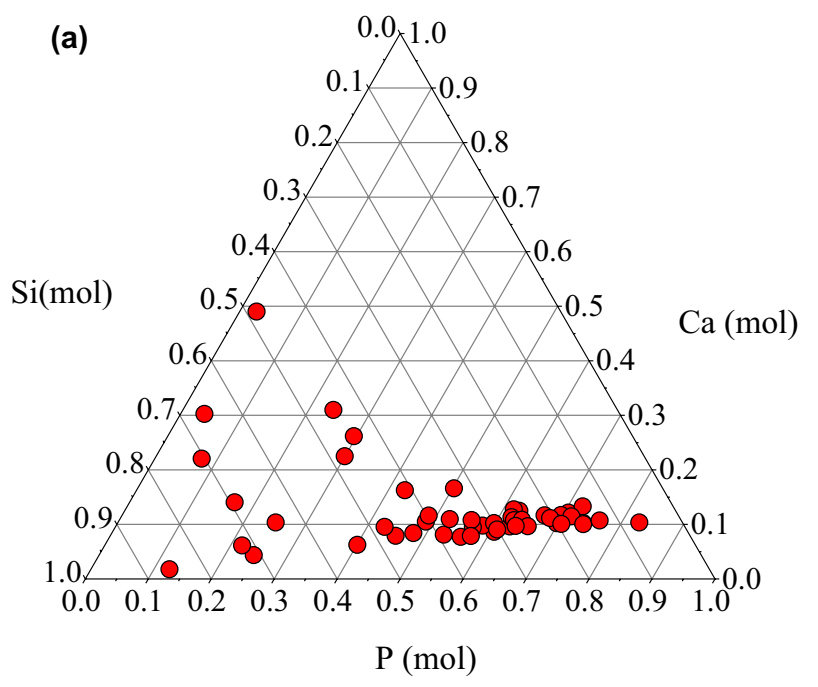

(b)

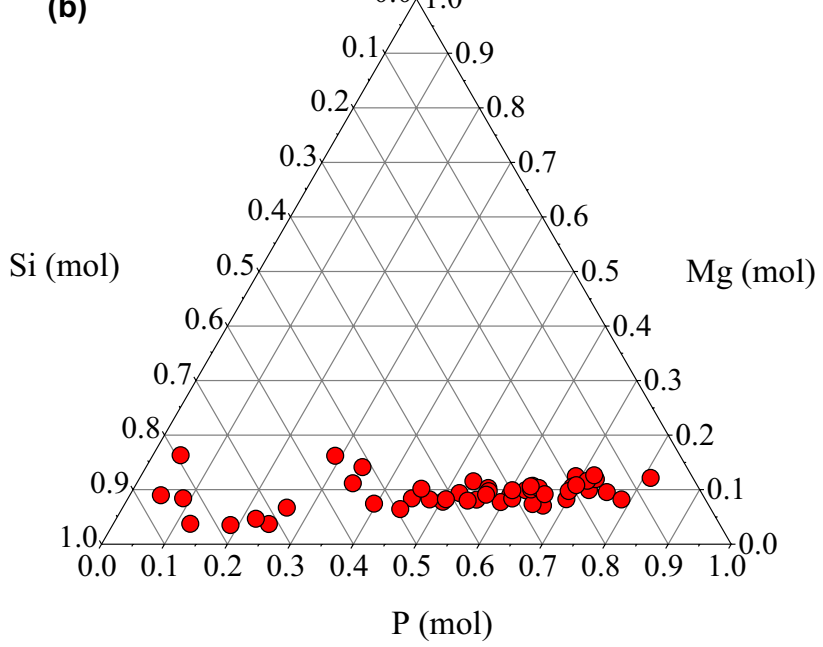

Fig. 11 Ternary diagrams between $\mathrm{P}$ and $\mathrm{Si}$ atoms with regard to $\mathrm{Ca}$ (a) and $\mathrm{Mg}$ (b) atoms in cement

- Phosphoric acid activation of volcanic ash at ambient temperature is an exothermic reaction and its described as a dissolution/precipitation process.

- The obtained product is hydrated and showed high early strength after $24 \mathrm{~h}$ of moulding. 

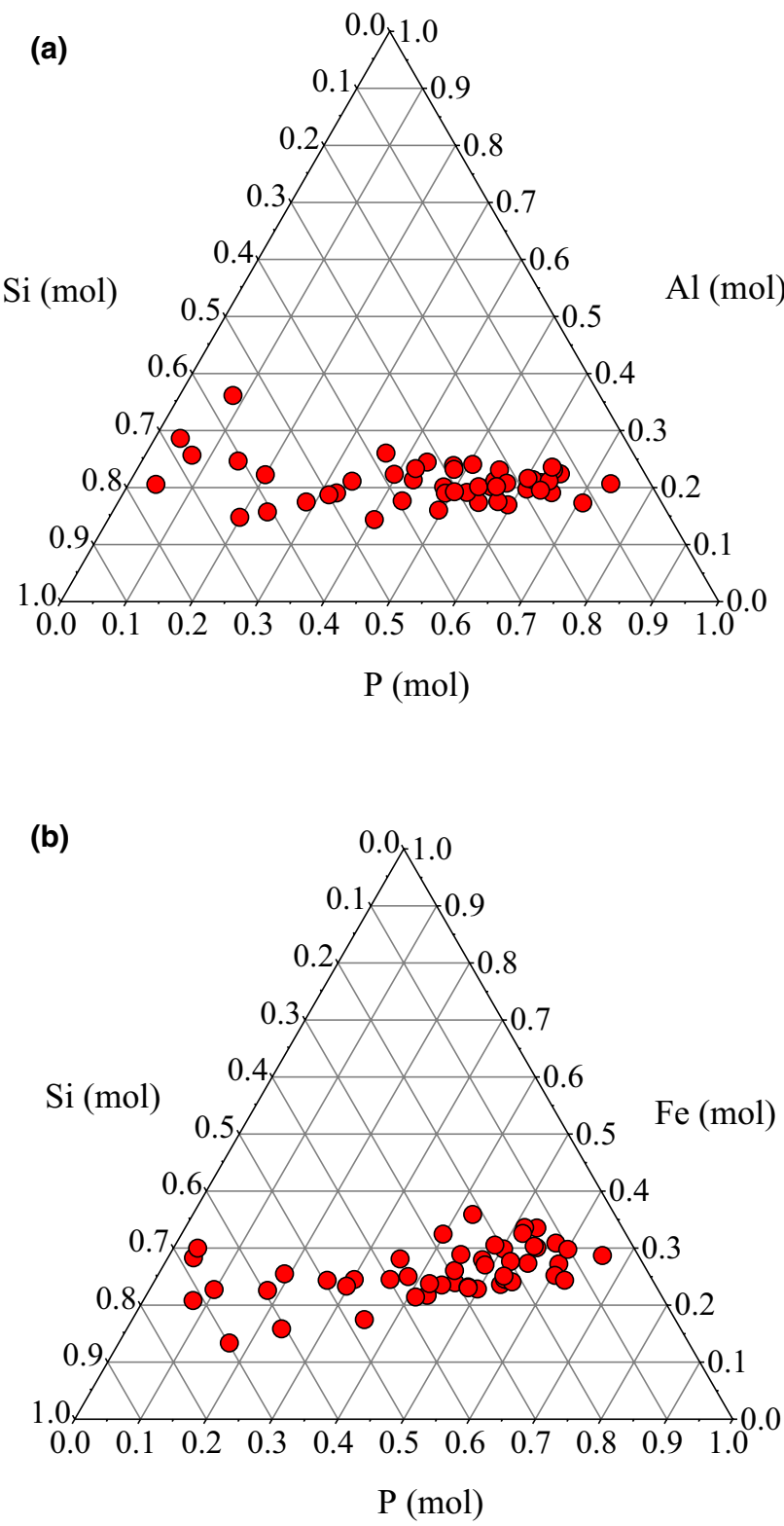

Fig. 12 Ternary diagrams between $\mathrm{P}$ and Si atoms with regard to Al (a) and Fe (b) atoms in cement

- SEM/EDS images revealed and confirmed the partial replacement of silicon by phosphorus atoms observed in the literature by FTIR. Nevertheless, more investigations on the contribution of other oxides $(\mathrm{CaO}, \mathrm{MgO}$ and $\mathrm{Fe}_{2} \mathrm{O}_{3}$ ) in acid activation of volcanic ash must be done.

- Phosphoric acid activation of volcanic ash is presented as the best of their utilization.

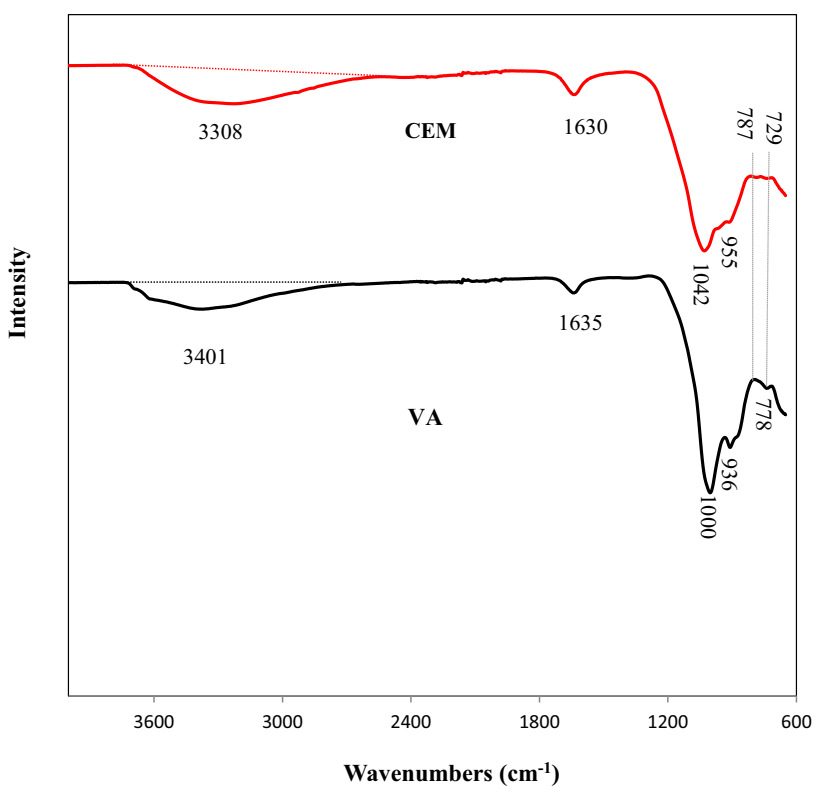

Fig. 13 FTIR of volcanic ash (VA) and cement (CEM)

Acknowledgements Dr. Djon Li Ndjock Benjamin Igor is grateful to "Laboratoire Matériaux et Durabilité des Constructions (LMDC)", INSA, Toulouse, France for its support in carrying out of this work.

\section{Compliance with ethical standards}

Conflict of interest The author declares that they have no conflict of interest.

\section{References}

1. Kamseu E, Leonelli C, Perera DS, Melo UC, Lemougna PN (2000) Investigation of the volcanic ash based cements as potential building materials. Inter Ceram Inter 58:136-140

2. Tchakouté HK, Elimbi A, Yanne E, Djangang CN (2013) Utilisation of volcanic ashes for the production of cements cured at ambient temperature. Cem Concr Comp 38:75-813

3. Lemougna PN, Melo UFC, Delplancke MP, Rahier H (2014) Influence of the chemical and mineralogical composition on the reactivity of volcanic ashes during alkali activation. Ceram Inter 40:811-820

4. Djobo JNY, Elimbi A, Tchakouté HK, Kumar S (2017) Volcanic ashbased cement cements/concretes: the current state of the art and perspectives. Environ Sci Pollut Res 24:4433-4446

5. Lemougna PN, Wang K, Tang Q, Nzeukou AN, Billong N, Melo UC, Cui X (2018) Review on the use of volcanic ashes for engineering applications. Res Conserv Recy 137:177-190

6. Robayo-Salazar RA, Mejía de Gutiérrez R (2018) Natural volcanic pozzolans as an available raw material for alkali-activated materials in the foreseeable future: a review. Constr Build Mater 189:109-118

7. Rafat S (2012) Properties of concrete made with volcanic ash. Res Conserv Recy 66:40-44 
8. Djon Li Ndjock BI, Elimbi A, Cyr M (2017) Rational utilization of volcanic ashes based on factors affecting their alkaline activation. J Non-Cryst Solids 463:31-39

9. Baenla J, Bike Mbah JB, Djon Li Ndjock Bl, Elimbi A (2019) Partial replacement of low reactive volcanic ash by cassava peel ash in the synthesis of volcanic ash based geopolymer. Constr Build Mater 227:116689

10. Robayo-Salazar RA, Mejía de Gutiérrez R, Puertas F (2016) Effect of metakaolin on natural volcanic pozzolan-based geopolymer cement. Appl Clay Sci 132-133:491-497

11. Soudée E, Péra J (2000) Mechanism of setting reaction in magnesia-phosphate cements. Cem Concr Res 30:315-321

12. SoudéeE Péra J (2002) Influence of magnesia surface on the setting time of magnesia-phosphate cement. Cem Concr Res 32:153-157

13. Wagh AS, Jeong SY (2003) Chemically bonded phosphate ceramics: I, A dissolution model of formation. J Am Ceram Soc 86:1838-1844

14. Wagh AS, Jeong SY (2003) Chemically bonded phosphate ceramics: III, reduction mechanism and its application to iron phosphate ceramics. J Am Ceram Soc 86:1850-1855

15. Wagh AS, Grover S, Jeong SY (2003) Chemically bonded phosphate ceramics: II, warm temperature process for alumina ceramics. J Am Ceram Soc 86:1845-1849

16. Chau CK, Fei Q, Zongjin L (2011) Microstructure of magnesium potassium phosphate cement. Constr Build Mater 25:2911-2917

17. Zhang T, Chen H, Xiangyu L, Zhigang Z (2017) Hydration behavior of magnesium potassium phosphate cement and stability analysis of its hydration products through thermodynamic modeling. Cem Concr Res 98:101-110

18. Ding Z, Zongjin L (2005) Effect of aggregates and water contents on the properties of magnesium phospho-silicate cement. Cem Concr Comp 27:11-18

19. Yue $L$, Chen $B$ (2013) Factors that affect the properties of magnesium phosphate cement. Constr Build Mater 47:977-983

20. Zheng DD, Tao J, Can-Qiang W, Chun-Jing S, Xu-Jian L, Khandaker MAH (2016) Effect of the combination of fly ash and silica fume on water resistance of Magnesium-Potassium Phosphate Cement. Constr Build Mater 106:415-421

21. Ai-juan W, Zhi-long $Y$, Jiao Z, Lin-tao L, Jun-ming $L$, Zheng $L$ (2013) Effect of raw material ratios on the compressive strength of magnesium potassium phosphate chemically bonded ceramics. Mater Sci Eng C 33:5058-5063

22. Hou D, Handong Y, Jinrui Z, Penggang W, Zongjin L (2017) Experimental and computational investigation of magnesium phosphate cement mortar. Cem Concr Res 98:101-110

23. Chao Y, Jueshi Q, Jihui Q, Hongtao W, Qingzhen W, Ziqi Y (2015) Effect of early hydration temperature on hydration product and strength development of magnesium phosphate cement (MPC). Cem Concr Res 78:179-18919

24. Liu N, Chen B (2016) Experimental research on magnesium phosphate cements containing alumina. Constr Build Mater 121:354-360

25. Celerier $\mathrm{H}$, Jouin J, Mathivet $\mathrm{V}$, Tessier-Doyen $\mathrm{N}$, Rossignol $\mathrm{S}$ (2018) Composition and properties of phosphoric acid-based geopolymers. J Non-Cryst Solids 493:94-98

26. Tchakouté $\mathrm{HK}$, Rüscher $\mathrm{CH}$, Kamseu $\mathrm{E}$, Andreola $\mathrm{F}$, Leonelli $\mathrm{C}$ (2017) Influence of the molar concentration of phosphoric acid solution on the properties of metakaolin-phosphate-based geopolymer cements. Appl Clay Sci 147:184-194

27. Mohamed K, Hosnia K, Mohamed M, Chiara Z, Mahmoud D, Dondib M, Srasraa E (2017) Interaction of metakaolin-phosphoric acid and their structural evolution at high temperature. Appl Clay Sci 146:510-516

28. Bewa N, Tchakouté HK, Claus HR, Kamseu E, Leonelli C (2019) Influence of the curing temperature on the properties of poly(phospho-ferro-siloxo) networks from laterite. SN Appl Sci $1: 1-12$

29. Louati S, Hajjaji W, Baklouti S, Samet B (2014) Structure and properties of new eco-material obtained by phosphoric acid attack of natural Tunisian clay. Appl Clay Sci 101:60-67

30. Chengying B, Alberto $C$, Paolo $C$ (2017) Open-cell phosphate-based geopolymer foams by frothing. Mater Letters 188:379-382

31. Katsiki A (2019) Aluminosilicate phosphate cements-a critical review. Adv Appl Ceram 118:274-286

32. Perera DS, Hanna JV, Davis J, Blackford MG, Latella BA, Sasaki $Y$, Vance ER (2008) Relative strengths of phosphoric acidreacted and alkali-reacted metakaolin materials. J Mater Sci 43:6562-6566

33. Gualtieri ML, Romagnoli M, Pollastri S, Gualtieri AF (2015) Inorganic polymers from laterite using activation with phosphoric acid and alkaline sodium silicate solution: mechanical and microstructural properties. Cem Concr Res 67:259-270

34. Louati S, Baklouti S, Samet B (2016) Acid based geopolymerization kinetics: effect of clay particle size. Appl Clay Sci 132-133:571-578

35. Louati S, Baklouti S, Samet B (2016) Geopolymers based on phosphoric acid and illito-kaolinitic clay. Adv Mater Sci Eng. https://doi.org/10.1155/2016/2359759

36. Tchakouté HK, Rüscher CH (2017) Mechanical and microstructural properties of metakaolin-based cement cements from sodium waterglass and phosphoric acid solution as hardeners: a comparative study. Appl Clay Sci 140:81-87

37. Wang YS, Jian-Guo D, Ding Z, Wei-Ting X (2017) Phosphatebased cement: formation mechanism and thermal stability. Mater Lett 190:209-212

38. Gao XX, Cyr M, Multon S, Sellier A (2013) A comparison of methods for chemical assessment of reactive silica in concrete aggregates by selective dissolution. Cem Concr Compos 37:82-94

39. Dupain R, Lanchon R, Saint-Arroman J.C (2000) Granulats, sols, ciments et bétons. Caractérisation des matériaux de génie civil par les essais de laboratoire. Casteilla, $2^{\mathrm{e}}$ édition conforme aux normes européennes

40. Lemougna PN, MacKenzie KJD, Jameson GNL, Rahier $\mathrm{H}$, Melo UFC (2013) The role of iron in the formation of inorganic polymers (geopolymers) from volcanic ash: ${ }^{57} \mathrm{Fe}$ Mössbauer spectroscopy study. J Mater Sci 48:5280-5286

41. Ai-Juan W, Jiao Z, Jun-ming L, An-bo M, Lin-tao L (2013) Effect of liquid-to-solid ratios on the properties of magnesium phosphate chemically bonded ceramics. Mater Sci Eng 33:2508-2512

42. Sow M, Hot J, Tribout C, Cyr M (2015) Characterization of spreader stoker coal fly ashes (SSCFA) for their use in cementbased applications. Fuel 162:224-233

43. Zribi M, Samet B, Baklouti S (2019) Mechanical, microstructural and structural investigation of phosphate-based geopolymers with respect to P/AI molar ratio. J Solid State Chem 281:121025

Publisher's Note Springer Nature remains neutral with regard to jurisdictional claims in published maps and institutional affiliations. 